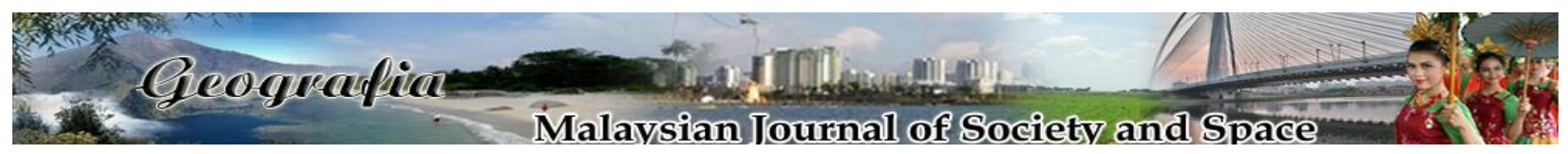

\title{
Bicycle lane planning: A site appraisal in Fukuoka, Japan
}

\author{
Syakir Amir Ab Rahman ${ }^{1}$, Lukman Hakim Mahamod ${ }^{1}$, Muhammad Afiq Hakimi Ismail ${ }^{1}$, Wan \\ Muhammad Hafizi Wan Mansor ${ }^{1}$, Safwan Sharit ${ }^{1}$, Muhammad Hafizi Zukrey ${ }^{1}$, Muhammad Hafizuddin \\ Hanafi ${ }^{1}$, Muhammad Alif Khidhir Mohammad Aidid ${ }^{1}$, M. Zainora Asmawi ${ }^{1}$, Zakiah Ponrahono ${ }^{2}$, Nor \\ Nadiah Najib ${ }^{3}$ \\ ${ }^{1}$ Department of Urban and Regional Planning, Kulliyyah of Architecture and Environmental Design, \\ International Islamic University Malaysia \\ ${ }^{2}$ Department of Environment, Faculty of Forestry and Environment, Universiti Putra Malaysia \\ ${ }^{3}$ Research and Development Division, PLANMalaysia
}

Correspondence: Syakir Amir Ab Rahman (email: syakiramir@iium.edu.my)

Received: 06 March 2021; Accepted: 19 August 2021; Published: 27 August 2021

\begin{abstract}
Cycling is one of the most sustainable modes to commute from one place to another. However, not everyone views bicycles as a fundamental component of the overall transportation system because presently, societies are heavily reliant on private vehicles. In reality, most see it only as a tool for recreational and exercise purposes. This paper seeks to identify the planning and design of bicycle lanes in Fukuoka, Japan. The research applies the site appraisal technique which involves gathering information about comparable site values within four areas i) Hakata station, ii) Ohori Park and Nishi Park, iii) Island city and iv) Fukuoka residential area. The findings identified various policies, guidelines and designs for bicycle infrastructure in Japan. There are significant differences between bicycle road, bicycle lane and sidewalks in Japan and Malaysia. Some of the findings show that Japan is gearing towards an even more bicycle friendly environment with the promulgation of the Promotion of Bicycle Use Act. However, there are also some setbacks such as the ineffectiveness of colored lanes to differentiate between bicycle lanes and pedestrian or vehicle lanes. Malaysia needs a blueprint and guidelines at the state and local levels to designate bicycle lanes and guarantee users' safety and enjoyment. A specific unit for cycling in transportation related agencies is proposed to make Malaysia a bicycle-friendly city.
\end{abstract}

Keywords: Bicycle, bicycle lane planning, Fukuoka, Japan

\section{Introduction}

Globally, cycling is used for two main purposes. There are those who view cycling as one of the basic components of a transportation system. It can be used as a complementary transportation system to arrive at a destination. On the other hand, some view cycling as merely a tool for 
recreational purposes as modern societies become more auto-dependent and cities are planned to be car-oriented (Borgnat et al., 2011). Most countries nowadays have encouraged their cities to increase bicycle transportation to improve health and activities, reduce fuel consumption and greenhouse gas emissions (Ganiron, 2017), reduce congestion (Ryley, 2006), improve air quality, improve social interaction (Syakir Amir et al., 2020) and reduce vehicles (Shaheen et al., 2010). Bicycle transportation is encouraged in cities when the governments are conscious and aware of its advantages. Bike lanes or cycle lanes are types of bikeways, allocating lanes on the roadway for cyclists. Only bicycles or pedestrians are allowed to use the lanes and motorized vehicles are prohibited to ensure the safety of pedestrians and cyclists. Medard de Chardon et al. (2017) claim that cities with separated bike lanes had $44 \%$ fewer road fatalities and $50 \%$ fewer serious injuries from crashes. Safety is further improved in cities where bike lanes were separated from car lanes with physical barriers.

In Japan, cycling is a widely accepted transportation mode, even though Japanese cities have not yet developed wide cycling networks (Fishman et al., 2014; Stinson \& Bhat, 2003). Japanese urban plans are limited to two main actions related to cycling; either implementing bicycle parking facilities around railway/subway stations, or establishing bicycle zones within road intersections. Apart from that, the increase in bicycle ownership in Japan has neither been accompanied by corresponding policy guidance from the government nor by facility provision from the public sector. Despite the fact that bicycles are favored by the general public, they still remain of secondary importance in the Japanese transport community.

The study area is in Fukuoka prefecture, Japan. Fukuoka is the capital city of Fukuoka Prefecture, situated on the northern shore of the Japanese island of Kyushu. It is the most populous city on the island and the largest city and metropolitan area west of Keihanshin. In Japan, the transportation system, including bicycles, is managed under the Ministry of Land, Infrastructure, Transport, and Tourism Japan (MLIT). All criteria in the allocation of roads and transportation facilities are stated in guidelines by the Ministry of Land, Infrastructure, Transport, and Tourism Japan (MLIT). This study aims to identify issues regarding bicycle lane planning in Fukuoka and to assess the service provision of bicycle road/lane in the study area as well as the policies related to it.

\section{Literature Review}

As of 2016, there are three acts that are directly related to planning of bicycle lanes in Japan. Those acts are - i. Development of Bicycle Paths Act No. 16; ii. Comprehensive Promotion of Safety of Biking and Parking Spaces for Bicycles Act No. 87; and iii. Promotion of the Uses of Bicycles Act No. 113 (Ministry of Land, Infrastructure, Transport and Tourism, 2015). These acts play fundamental roles in gearing Fukuoka and Japan towards a more bicycle friendly city. The latest act that relates to bicycle use was Act No. 113, promulgated back in 2016. The fundamental principle of this act is to encourage the usage of bicycle mode for the benefit of the public and social welfare, reducing the emission of carbon dioxide, as well as supply and prepare mobility during disaster. It is also to improve public health and reduce traffic congestion by minimizing vehicle dependency. In short, the act is aimed to improve the bicycle mode functions in the transportation system, thus increasing its utilization and efficiency. Under the law, cyclists are required to use bicycle roads whenever the service provision is available. At present, the bicycle lanes are still limited, and most of it are provided as a part of tourism and recreational purposes 
instead of as an integral part of transportation. Thus, Act 113 helps set the ground work needed for better bicycle lane planning in Japan.

In Japan, urban transportation plans often treat bicycle and walking as a single mode, despite the numerous bicycle users (Corcoran et al., 2014). Car limitation policy has induced more people to travel by cycling. In response to this sudden influx of bicycle traffic, the government focused on either implementing bicycle parking facilities around railway/subway stations, or establishing bicycle zones in road intersections (Kobayashi et al., 2014).

Traffic regulations were waived between 1965 to 1975 to ensure that sidewalks are used by cyclist. From there on, bicycle and pedestrian lanes have been constantly provided by the government, separate from other mode of vehicles. Countermeasures were also implemented to reduce bicycle-pedestrian accidents. In 2008. MLIT launched a plan to establish an extensive bicycle lane network nationwide. Although the network is not as lengthy as other advanced countries that are engaged in bicycle lane planning, it serves for a better cycling environment in Japan (Ministry of Land, Infrastructure, Transport and Tourism, 2015). Later in 2012, MLIT and NPA introduced an investigative committee to offer a safe and pleasant environment for cyclists. As a result, the committee established "Recommendation for safe and pleasant cycling environment for everyone" and subsequently, they created "guideline for creating a safe and pleasant cycling environment" to assist road authorities and police to actively participate in planning road networks for cyclists while promoting awareness.

\section{Guidelines on bicycle lane planning in Japan}

The guideline for development of safe and comfortable bicycle facilities was published by the Ministry of Land, Infrastructure, Transport and Tourism (2015). The process of bicycle planning in Fukuoka takes into account factors such as:

- Each part of the road widths including vehicle lanes, median, road shoulders, side strips, parking lanes, sidewalks and green belts are reviewed. It is to examine the readjustment and provision of road spaces.

- Reduction of vehicle lane quantity, changing road circulation to a one-way road, manging traffic demand to control vehicle traffic on the road.

- Restriction of vehicle speed on the roads, monitoring of vehicle speed limits and revision of bicycle travelling space categories.

- Roads connecting landmarks (stations, bicycle-parking areas, sightseeing spots, public facilities, and so on),

- Roads where many accidents with cyclists occur,

- Roads where bicycle use should be encouraged,

- Roads around places where a landmark is planned to be located,

- Roads where bicycle facilities are already developed, and

- Roads which are necessary to connect the network.

In a situation where providing specific bicycle travelling space is complicated, a short-term space for bicycle or alternative route should be considered. Th guidelines requires a study of temporary or short-term bicycle travelling spaces to design the bicycle network, rather than abandon the route due to the difficulties. As Japan is evolving toward a bicycle-friendly city, this guideline will help to steer them towards achieving their goals. 


\section{Enforcement}

All bicycles must have a working front lamp and reflector at the rear. Bells are supposedly a legal requirement but this is not enforced, and conflicting reports from authorities in Japan even mention that using a bell on the sidewalk is illegal. Bicycle insurance is required in Japan and bicycles must be registered with local authorities. Registration with local authorities costs just 500 yen and can be done when purchasing bicycles. Foreign residents or visitors should always have a passport or Japanese government issued ID. The police can, and do, stop cyclists to check ownership and carrying these documents at all times is a legal requirement for non-Japanese.

Given the significant increase in accidents relating to pedestrians and cyclists, Japan has taken a few countermeasures to reduce the occurrence of such accidents (Corcoran et al., 2014). They include:

- Education on traffic rules through distribution of flyers with the assistance of local community.

- Guidance and control of traffic regulation violators through use of bicycles

- Provision of incentives to comply with the rules by distributing bicycle licenses at elementary schools

- Measurements to cope with parked and loading/unloading vehicles - banning of parking along the road in commuting zones

- Measure to control abandoned or illegally parked bicycles - development of bicycle parking in cooperation with railroad operators

- Promotion of use of bicycles that include bicycle map.

\section{Methodology}

This study was conducted in Fukuoka, Japan. It focuses on a few selected areas within the city's boundary. The areas are: i) Hakata station, ii) Ohori Park and Nishi Park, iii) Island city and iv) Fukuoka residential area. A site appraisal and inventory was administered to study the current situation of bicycle lane planning in Fukuoka as well as gauge its level of conformity with the latest guidelines by Ministry of Land, Infrastructure, Transport and Tourism. The site inventory components were designed to explore the extent of bicycle lane provision in Fukuoka. It includes measuring, observing and photo taking of the related subjects in the respective four study areas. These steps provide data pertaining to measurements and supporting facilities for cyclists within the study areas. The site appraisal was conducted in 1 week. Mapping and content analysis will be used to present data on current policies, acts and enforcement regarding bicycle planning in Japan, specifically in Fukuoka.

\section{Results and Discussion}

Site appraisal of study areas

The study areas are divided into three main areas according to their primary functions which are commercial, recreational, residential and industrial. The sites are chosen based on other case studies which are Hakata Station, Ohori Park, Nishi Park, Island City, residential area near Guell Hakata Hotel and other parks as well. 


\section{a. Commercial}

The commercial area studied is situated around Hakata Station. The area is considered an urban area where there are many commercial activities and also serves as the center of public transportation. Figure 1 shows the map of the area studied around Hakata Station. The numbers (1-10) refer to hotel accommodations adjacent to Hakata Station.

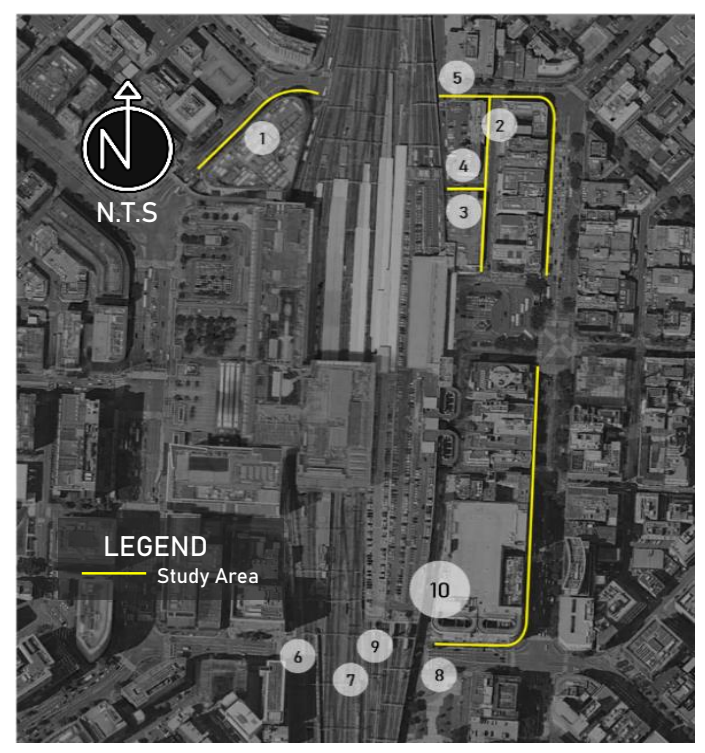

Figure 1. Layout of Hakata Station

There are some bicycle lanes around Hakata Station. The most common type of cycling lane provided is bicycle lanes that have been demarcated from the existing road space. Bicycles and other transportation modes share the same carriageway and the colored road shoulders and markings indicate the cyclists' routes or lanes. Figure 2 shows the bicycle lane provided around Hakata Station.

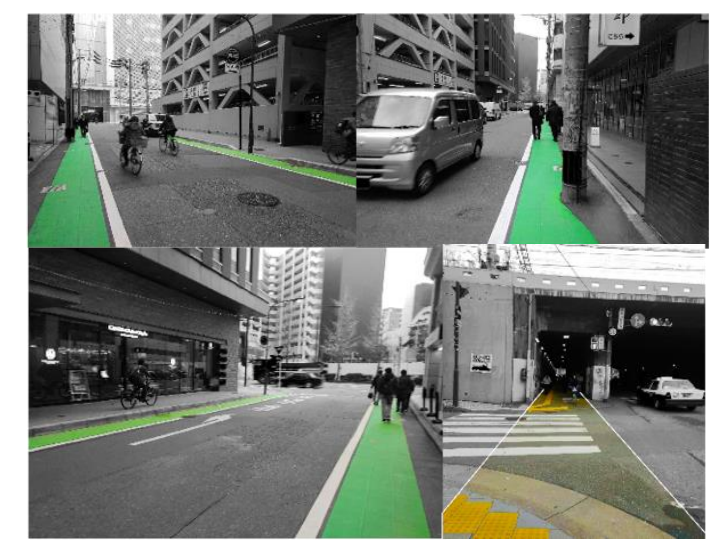

Figure 2. Bicycle lanes around Hakata Station (Kuko-duri Street \& Chikushi-dori Street)

Other than that, there are also shared sidewalks for cyclists and pedestrians. This facility can be seen along the main road where the traffic volumes are larger. These sidewalks comply 
with the guidelines provided by the Ministry of Land, Infrastructure and Tourism Japan where the size of sidewalks should be at least 3.5 meters wide. Figure 3 shows the shared sidewalks for cyclists and pedestrians in the study area.

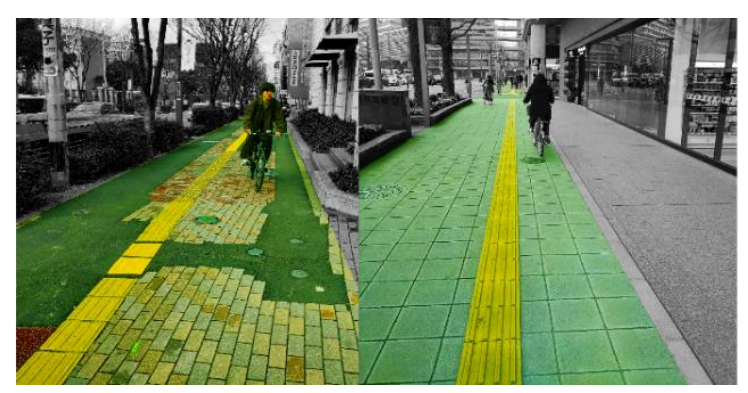

Figure 3. Shared sidewalks around Hakata Station (Hakataekichuogai Street)

It was found that the cycling lanes around Hakata Station are bicycle lanes and shared sidewalks between pedestrian and cyclist. The safety of the users is a concern as there is no clear boundary or area provided between cyclists and pedestrians. This issue of safety is worsened by the narrow roads around the station that can increase the number of accidents between cyclists and road users. Some cyclists are also not using the bicycle lanes provided, cycling on the roadway along with the motorized vehicles. This situation is very dangerous for all road users.

\section{b. Residential and Industrial}

For the residential area, there are two case studies involved which are Island City and Guell Hakata Hotel area. The map for Guell Hakata Hotel residential area is shown in Figure 4. The numbers (1-3) indicate the three streets covered in the study area.

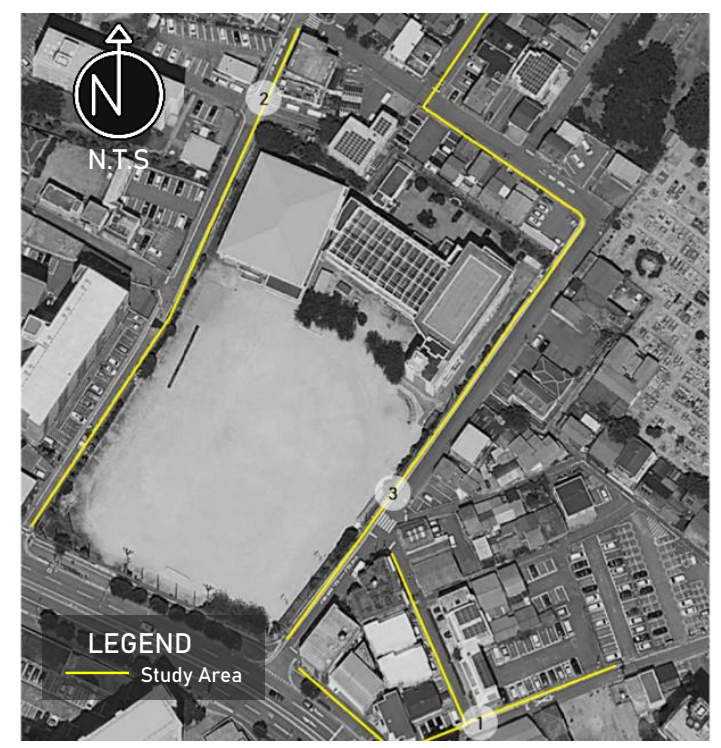

Figure 4. Bicycle lanes around Guell Hakata Hotel.

In the area, only one type of cycling lanes was identified which is bicycle lane. The lanes are provided to accommodate the needs for cyclists to move around the residential area. These 
lanes are provided along the service roads that are connected to the main road. Figure 5 shows the pictures of bicycle lanes in the residential area.

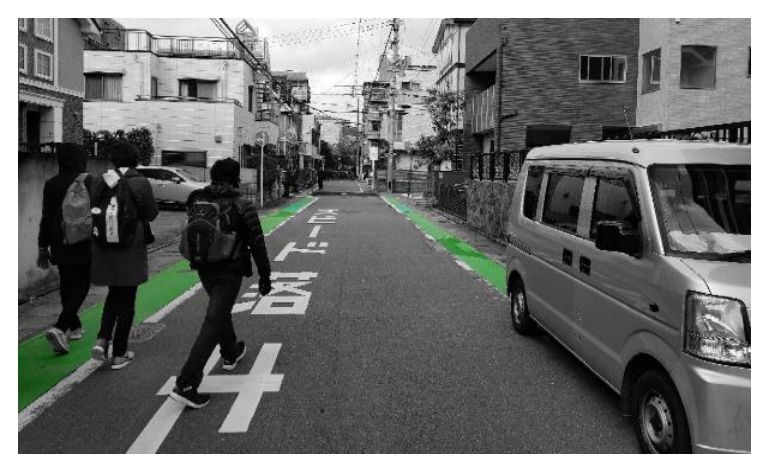

Figure 5. Bicycle lane in front of Guell Hakata Hotel

In Island City, there are several types of cycling lanes provided for public usage. This is because Island City is considered a mix of residential and industrial areas as there are both houses and a port that carries out industrial activities. Figure 6 shows the map of the study area within Island City. In the area, there are four types of cycling lanes identified. The cycling lanes include bicycle road, bicycle lane, sidewalks shared between pedestrians and cyclists with markings and sidewalk shared with pedestrians with no markings on it. Figure 7 shows the location and example of cycling lanes in Island City. The numbers illustrate the four streets covered in the study area.

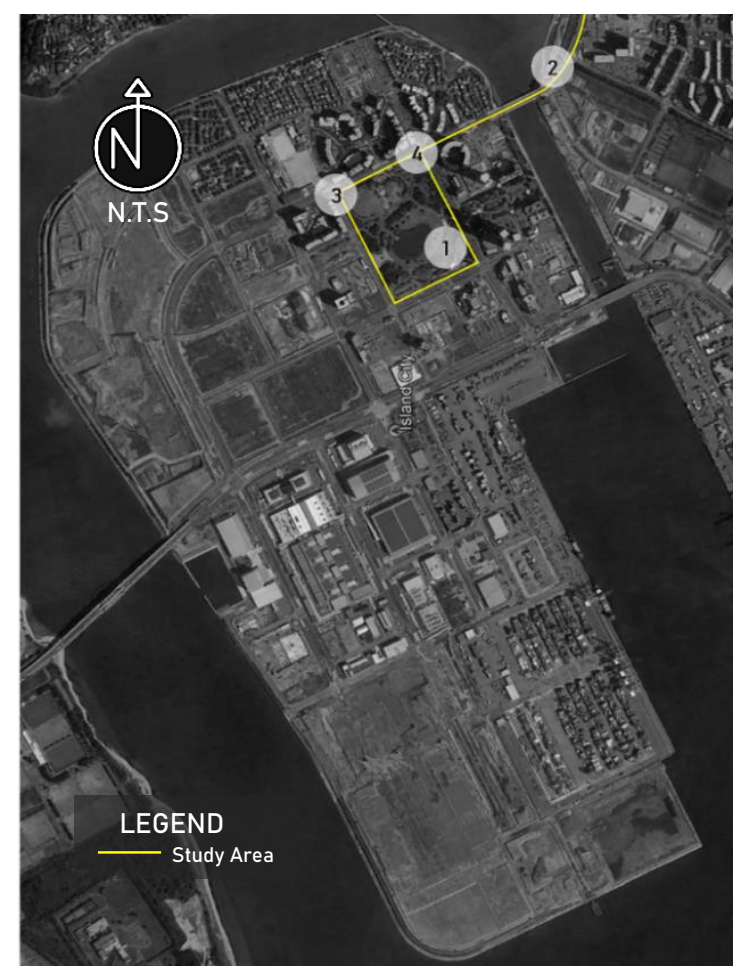

Figure 6. Bicycle lanes in Island City. 


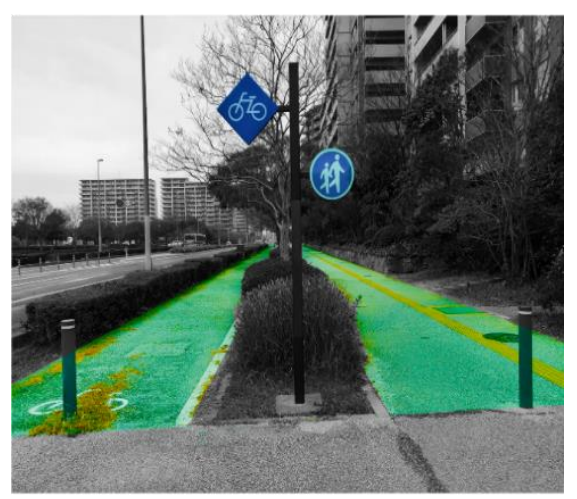

Figure 7. Bicycle lane around Island City

All the cycling lanes in Island City comply with the guidelines from the government. The bicycle road is also wider or equal to 2 meters so it is convenient for cyclist using the dedicated lanes. The shared sidewalks between cyclists and pedestrians with markings and no markings are also in compliance with guidelines, allowing 3.5 meters for both pedestrian and bicycle lanes. The sidewalks are well-maintained as the color of the sidewalks are still attractive and the condition of the sidewalks are still good. Additionally, the sidewalks are clearly segregated and safe for the users. However, the bicycle lane on the Aitaka Bridge is in the center of the bridge. This design is very dangerous for both cyclists and pedestrians.

\section{c. Recreational}

The recreational areas studied are Ohori Park, Nishi Park and other smaller parks. Based on observation, the types of cycling lanes in these parks are shared sidewalks between cyclists and pedestrians with markings and no markings. These bicycle lanes are combined with the pedestrian and jogging lanes but the size of the sidewalks is adequate to cater for both the cyclists and pedestrians.

\section{Comparison of bicycle lane in Fukuoka and Kuala Lumpur}

\section{a. Planning of cycling lane}

There are clear differences in management of cycling facilities between Malaysia and Japan. The first one is cycling lanes in Malaysia cannot be constructed by reducing the number of vehicular lanes. For example, reducing a 2 lane road to a one lane road to include a bicycle lane can cause an overload of vehicular traffic, especially in Kuala Lumpur. This situation is different in Japan where reducing lanes to construct a dedicated bicycle lane is a common practice. Other than that, the predetermined capacity of the road for vehicular traffic cannot be changed in Malaysia.

\section{b. Cycling lanes in Fukuoka and Kuala Lumpur}

In Japan, especially in Fukuoka, there are 4 types of cycling lanes that are being implemented in the design of cycling spaces. In Malaysia, cycling spaces are divided into two categories which 
are exclusive cycle track and non-exclusive cycle track. In Fukuoka, there are a few types of bicycle lanes. These bicycle lanes differ based on the adjusted speed limits as well as the readjustment of space for bicycle lanes by authorities. The initial assumption is the types of bicycle lanes are different based on the primary activities of the place. The bicycle lane facilities are divided into four categories which are bicycle road, bicycle lane, sidewalks shared between pedestrian and cyclist with markings and sidewalk shared with pedestrian with no markings on it.

\section{i. Bicycle road}

Bicycle-only road space is structurally separated from the roadway using, for example, a curb line. The space for cyclists is separated from the carriageway where the motorized vehicles are. This type of bicycle facility provides the highest level of safety that avoid conflicts and accidents with road pedestrian and other road users. Figure 9 shows the cross-section illustration of a bicycle road in Fukuoka. The width requirement for bicycle roads in Japan is at least 3 meters wide. (Ministry of Land, Infrastructure, Transport and Tourism, 2015)

\section{ii. Bicycle lane}

According to the traffic regulations in Fukuoka City, bicycle lanes are provided only for cyclists. Those lanes were designed by realigning road spaces and width by reducing motor vehicle lanes. The bicycle lane is included in the carriageway together with the road spaces. Hull \& O'Holleran (2014), defined bicycle lane as specific portions of the roadway that are designated by striping, signage, and pavement markings for exclusive use of bicycles. The bicycle lanes in Fukuoka are either marked with lines or colored pavement such as blue, green and red. Furthermore, the bicycle lanes in Fukuoka are mostly conventional bike lanes which are adjacent to motor vehicle travel lanes and flow in the same direct as car traffic. Figure 10 shows the cross-section illustration of a bicycle lane.

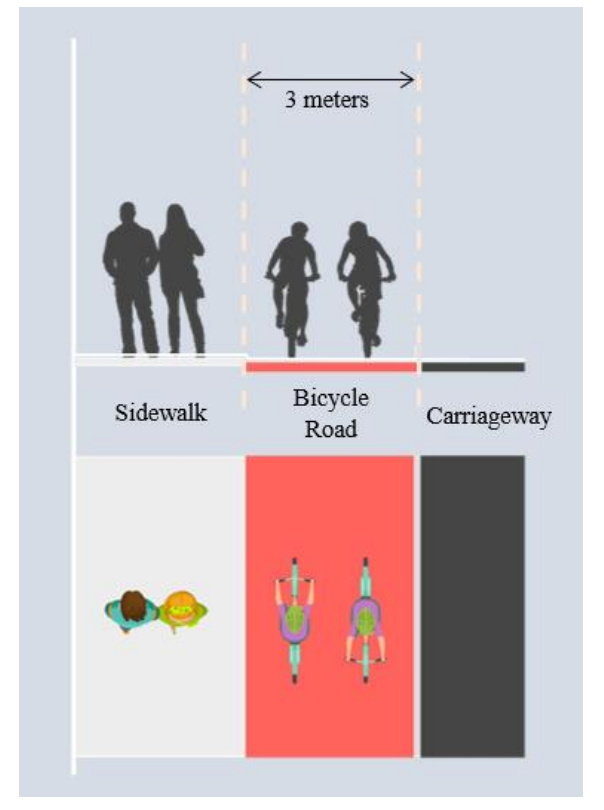

Figure 9. Cross-section of bicycle road

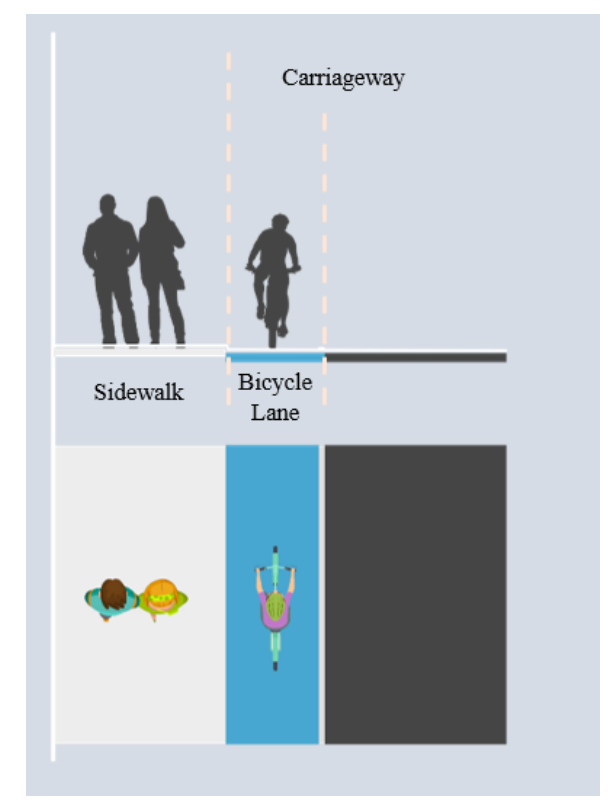

Figure 10. Cross-section of bicycle lane 
iii. Sidewalks shared between pedestrians and cyclists with markings

Another type of bicycle lane is bicycle lane facilities that are shared with pedestrian sidewalks. However, the pedestrian and cycling lanes are segregated by markings that are important to serve as a tool to separate the bicycle lanes from pedestrian walkways on the sidewalk. Figure 11 shows a cross-section illustration of a shared pedestrian and cyclist sidewalk with markings. The sidewalks should be at least 3.5 wide for shared bicycle and pedestrian lanes (Ministry of Land, Infrastructure, Transport and Tourism, 2015).

\section{iv. Sidewalk shared with pedestrian with no markings}

The last type of cycling lane is the same as the one before but with no markings. This type of cycling lane poses the most risks and threat to the safety of both pedestrians and cyclists. It may increase the chance of accidents as there are no clear separation signs or demarcation to segregate the sidewalk for the usage of both pedestrians and cyclists. Figure 12 shows the cross-section illustration of a sidewalk shared between cyclists and pedestrians with no markings on it. The required width of the sidewalks is the same as sidewalks with markings as it should be at least 3.5 wide for shared bicycle and pedestrian lanes (Ministry of Land, Infrastructure, Transport and Tourism, 2015).

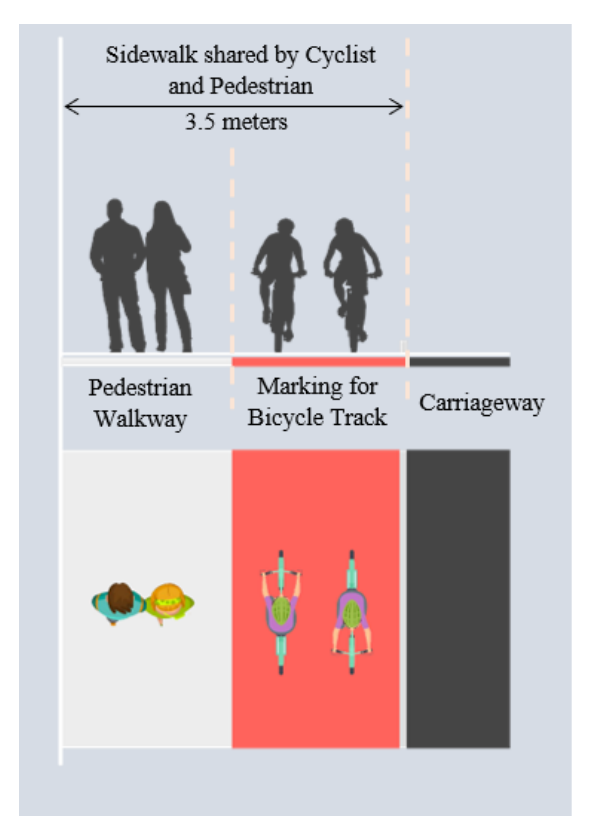

Figure 11. Cross-section of shared sidewalk with markings

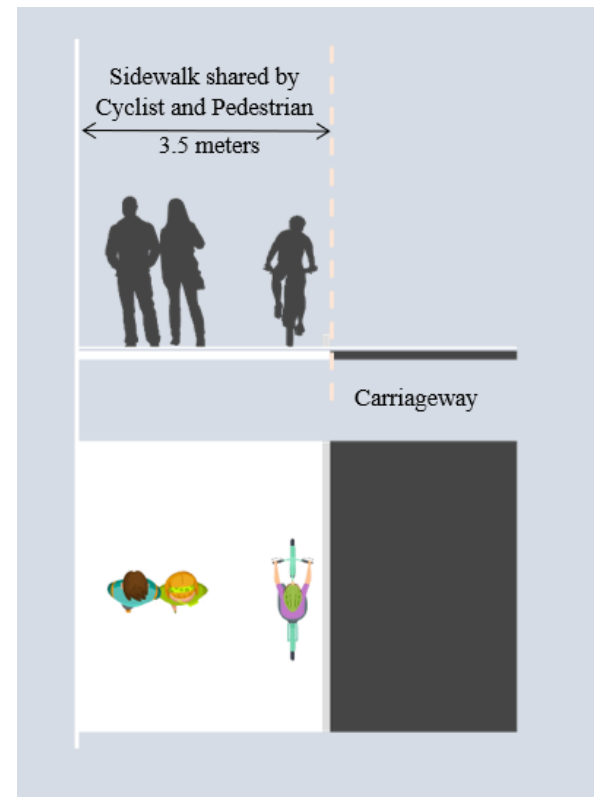

Figure 12. Cross-section of shared sidewalk without markings

In Malaysia, cycling spaces are categorized into two categories which are exclusive cycle tracks and non-exclusive cycle tracks. The exclusive cycle track is a portion of road that is dedicated for cyclist only and is off-carriageway such as bicycle road and shared lane with pedestrians while non-exclusive cycle track includes the on-carriageway track type such as bicycle lane. 
As seen in the Figure 13, there is a significant difference in terms of size and design of bicycle lanes between Malaysia and Japan as mentioned before in the previous chapter. For example, in Japan, the minimum size of bicycle road or exclusive cycle track is $3 \mathrm{~m}$ and shared sidewalks for pedestrians and cyclists is at least $3.5 \mathrm{~m}$. This requirement is clearly more convenient for cyclists than the requirement provided in Malaysia which is just $2.5 \mathrm{~m}$ for exclusive tracks.
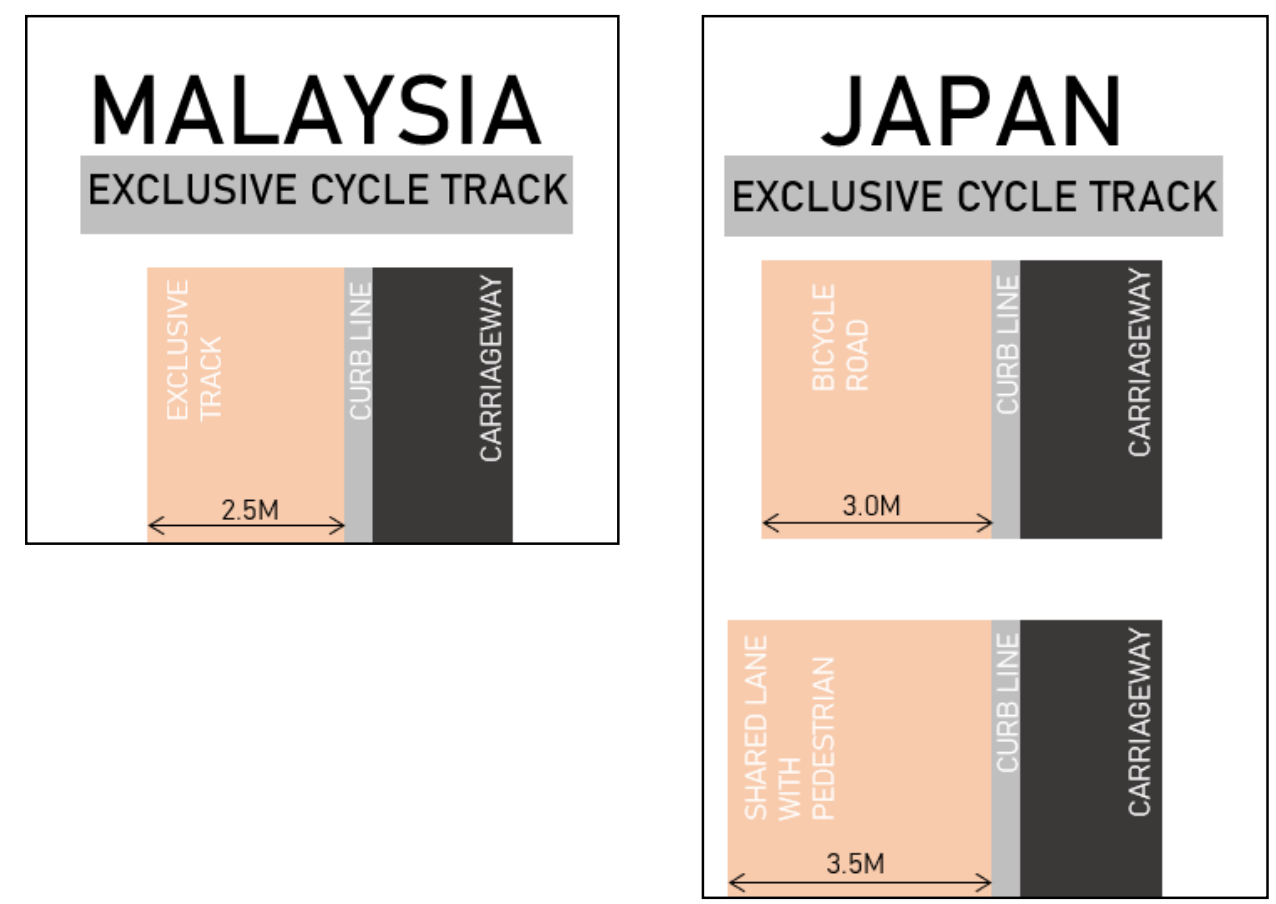

Figure 13. Exclusive cycle track Malaysia and Japan.

\section{Discussion}

Every development, either physically or strategically, requires references, guidelines, frameworks and legal acts to form a blueprint to guide and ensure that the goal of the program or project is achievable while meeting the needs and standards that take into account the strength, weaknesses, opportunities and threats involved. The standard legal acts or guidelines that have been enacted by the government need to serve as the main references for planning and development because this would help to standardize the programs. Klemm (2018); Russo et al. (2016); Larsen (2007); Haase et al. (2008) corroborated that blueprints for programs and projects, particularly in the city context, should be provided according to the needs of the environment, people and situations. Without good reference, guidelines or framework in city development, it would be a problem for future and existing decision makers to measure and monitor the effectiveness of projects and programs that have been put into motion. It will inhibit the improvement and enhancement of current and future planning and development programs. Hence, framework and guidelines are needed as reference to achieve success in bicycle projects (O’Brien et al., 2013).

In Fukuoka, the ministry already has specific requirements, guidelines and acts for bicycle and cyclist under their road safety laws and regulations. This includes a set of guidelines for road space for cyclists, a planning process that covers the goal of cycling projects, identification of roads for bicycle routes and identification of categories of cycling spaces. This step has generated awareness and has provided encouragement for bicycle use among the authority and public. As an 
example, from the safety aspect, the ministry has set the guidelines for the amount of space for cycling based on the traffic trends. These can be divided into several categories; A, bicycle roads which requires physical separation between bicycles and automobiles for roads with automobiles travelling over $50 \mathrm{~km} / \mathrm{h}$; B, bicycle lanes or other roads that that need visual separation but do not fit in either category A or C; And C, carriageway (bicycle track with colored shoulder at left side of road) with no separation between automobiles and bicycles for roads with less traffic and automobiles travelling at low speed (below $40 \mathrm{~km} / \mathrm{h}$ or 4000 vehicles per day). All groups and classifications were determined based on speed limits, changes, and the rearrangement of road spaces for bicycle lanes or carriageways.

In comparison, projects or programs for bicycle usage in Malaysia usually takes place at the local authority level which means that there are no specific blueprints or guidelines from the federal level for provision of bicycle facilities and cycling laws. Most of it are implemented and applied by the local authority which in the case of this study, falls under DBKL as the local authority of Kuala Lumpur city. When this happens, the authority faces constraints in terms of planning and implementing programs and projects because there are no specific guidelines and framework for them. They need to start from basic formulation of goals and plans without a standard guideline. This could be effective in the short term but when dealing with long term situations and effects, there is a high risk of problems in executing and maintaining the project or program. This is because the current or future parties involved with the development of these bicycle projects have no references and updated guidelines to enhance and improve the programs as well as ensure the safety of the cyclists during the implementation phase. A stark difference can be seen between Type A bicycle roads in Fukuoka which separates cyclists and automobiles and Kuala Lumpur City Centre bike lanes which do not have physical separation between automobiles and cyclists when both similarly involve vehicles traveling at speeds of over $50 \mathrm{~km} / \mathrm{h}$.

The guidelines prepared by Japan Ministry take into consideration the speed of automobiles that may harm the cyclist. Thus, implementation of bicycle lanes must be accompanied by better references and guidelines to guarantee the safety of the users and also encourage people use bicycles as a mode of transportation. In San Diego and Sacramento, dedicated legislation and guidelines have led to the success of bicycling and walking projects (Zeeuw \& Flusche, 2011) and these were efficiently implemented in most of the urban areas to foster sustainable transport system, especially bicycle lanes, for the communities (Fleming, 2012; Hong et al., 2006; Noland \& Kunreuther, 1995). The success or effectiveness of bicycle programs start from basic and important governmental roles that would influence all aspects and factors in the project or programs. In fact, the goals of transportation sustainability in programs like low-carbon city and smart city are hardly achievable if the implementation is weak and lacks resources (Li et al. 2020, Lucic et al, 2020; Chehri \& Mouftah, 2019). The plan which includes the types, group and classes for bicycle facilities development relies on legal acts, frameworks and guidelines from the government. In Japan, the bicycle has become an important transportation mode in various industries. This is because of the provision of bicycle infrastructure and the citizen's awareness about the importance of bicycles and cycling lanes (Kokura et al., 2010). The creation of an extensive network of bicycle lanes will play a critical role in determining whether the large number of urban commuters will switch from other modes of transportation to cycling (Romanillos \& Austwick, 2016).

In Malaysia, the bicycle is not widely used and the facilities provided for this mode of transport are sometimes abused by other vehicle users. This is due to lack of awareness among the citizens as well as weakness of the authorities to implement and legally protect the bicycle users. 
Most Malaysians think constructing a bicycle lane will bring more harm than benefits. The bicycle lane will make already congested roads narrower and this would pose a safety risk towards the users, especially the cyclists. The traffic flow is also expected to be slower with the addition of a bicycle lane along the carriageway. Another argument is that the weather in Malaysia is not suitable for cyclists and the design of the bicycle lane is not appropriate. For example, the blue bicycle lane constructed by Kuala Lumpur City Hall resulted in accidents involving a few motorcyclists due to the separator installed to demarcate the bicycle lanes.

One way forward for Malaysia in transportation planning is to use bicycles as a supporting system in public transportation accessibility. By integrating bicycle lanes into transportation planning (Larsen \& El-Geneidy, 2011; Ortuzar et al., 2000), Malaysia will be steered towards a greener city with a smaller carbon footprint. Thus, it is important to conduct a detailed study on bicycle planning to suit Malaysia's equatorial heat and its residents' habits and preferences. As for recommendations, based on the findings, several actions can be taken from the comparison between bicycle lanes in Malaysia and Japan. A special department for bicycle facilities needs to be set up under the Ministry of Transportation or any transportation related agencies. This is to ensure that bicycle lanes are prioritized in road developments in Malaysia. Even though there are guidelines for bicycle lanes from several local authorities, but they do not promote connectivity and standardization.

By having a special department to handle cycling matters, the second recommendation is to have regulations and guidelines from the national planning department to ensure that every development includes bicycle lanes in its road development. The guidelines must include safety precautions and consideration of users from all level of ages. Bicycle lanes must be suitable for all ages and people (Hirsch, et al., 2019; Enquist \& Sebhatu, 2018; Efthymiou et al., 2013) including vulnerable groups (Roldan et al., 2013). Besides that, the bicycle lane planning should provide wide coverage and connectivity from one place to another (Hirsch et al., 2019; Lin et al., 2013) for the purpose of increasing bicycle usage among all walks of life. These guidelines can serve as direction for current development and act as references for better future developments. Lastly, along with the blueprints or guidelines from the federal government, collaboration between local authorities and the private sector needs to be enhanced. This is to ensure that all parties will take part in enhancing bicycle lanes in Malaysia. With these initiatives, cycling will be promoted widely in Malaysia

\section{Conclusion}

Some of the roads in Fukuoka are equipped with planter box on the side of the road making it a pleasant journey to cycle through, but it suffers from the same failings of all sidewalk level lanes in Tokyo. The lane disappears at intersections forcing pedestrians and cyclists to mix, and due to lack of education and awareness, the planters do little to keep pedestrians out of the bicycle lane. Simply painting the sidewalks with bicycle logo does not make a physical barrier that separates cyclists from pedestrians. It will inadvertently result in accidents between both groups. Additionally, these roads that are painted to turn it into a "bicycle lane" often have cars parking on it. These lanes not only disappear at pedestrian crossings, forcing pedestrians and cyclists to mix, but also completely disappear at bus stops, and at random driveways, including those of gas stations and convenience stores. The stop or start nature of these lanes, the fact they are too narrow to be bidirectional, and the lack of separation make cycling these lanes little different than cycling on the sidewalk. The fact an effort is being made is truly wonderful, but without good design and 
coordination between all the responsible municipalities the opportunities to implement world class cycling infrastructure will disappear. This goes both ways for Japan and Malaysia.

\section{References}

Borgnat, P., Abry, P., Flandrin, P., Robardet, C., Rouquier, J., \& Fleury, E. (2011). Shared bicycles in a city: A signal processing and data analysis perspective. Advances in Complex Systems, 14(03), 415-438.

Chehri, A. \& Mouftah, H.T. (2019). Autonomous vehicles in the sustainable cities, the beginning of a green adventure. Sustainable Cities and Society, 51.

Corcoran, J., Li, T., Rohde, D., Charles-Edwards, E., \& Mateo-Babiano, D. (2014). Spatiotemporal patterns of a Public Bicycle Sharing Program: The effect of weather and calendar events. Journal of Transport Geogra-phy, 41, 292-305.

Efthymiou, D., Antoniou, C. \& Waddell, P. (2013). Factors affecting the adoption of vehicle sharing systems by young drivers. Transport Policy, 29, 64-73.

Enquist, B. \& Sebhatu, S.P. (2018). Service innovation, sustainability and quality meeting city challenges in the age of accelerations. International Journal of Quality and Service Sciences, 10(4), 431-446.

Fishman, E., Washington, S., \& Haworth, N. (2014). Bike share's impact oncar use: Evidence from the United States, Great Britain, and Australia.Transportation Research Part D: Transport and Environment, 31,13-20.

Fleming, S. (2012). Cycle space: Architecture \& urban design in the age of the bicycle. Rotterdam: Nai010 publishers.

Ganiron, T. (2017). Effect of Bike Lane Infrastructure on Ridership. The Scientific World Journal, $74,36-52$.

Haase, D., Haase, A., Kabisch, S. \& Bischoff, P. (2008). Guidelines for the "perfect inner city". Discussing the appropriateness of monitoring approaches for reurbanization. European Planning Studies, 16(8), 075-1100.

Hirsch, J.A., Stewart, I., Ziegler, S., Richter, B. \& Mooney, S. (2019). Residents in Seattle, WA report differential use of free-floating bikeshare by age, gender, race, and location. Frontiers in Built Environment, 5(17).

Hong, Z., Zhiliang, W., \& Wei, L. (2006). Bicycle-based courier and delivery services in beijing: Market analysis. Transportation Research Board, 1954(80), 45-51.

Hull, A., \& O’Holleran, C. (2014). Bicycle infrastructure: Can good design encourage cycling? Urban. Planning and Transport Research, 2(1), 369-406.

Klemm, W. (2018). Developing green infrastructure design guidelines for urban climate adaptation. Journal of Landscape Architecture, 12(3), 60-71.

Kobayashi, H., Honda, H., Yoshida, H. (2014) Characteristics of bicycle travel in Japan and the basic concept of the Bicycle Travel Space Development Guideline. Urban Transport, 3.

Kokura, M., Suga, M., Lee, B. , Shirakawa, K., Suwa, T., \& Ohmori, N. (2010) Safety and Enjoyability Evaluation of Roads and Streets for Bicycles: Case Studies of Bicycle Maps from Utsunomiya and Chigasaki, Japan. Journal of Maps, 6(1), 199-210.

Larsen, J., \& El-Geneidy, A. (2011). A travel behavior analysis of urban cycling facilities in Montréal, Canada. Transportation Research Part D: Transport and Environment, 16(2), 172-177. 
Larsen. K. (2007). New urbanism's role in inner-city neighbourhood revitalization. Housing Studies, 20(5), 795-813.

Lin, J.R., Yang, T.H. \& Chang, Y.C. (2013). A hub location inventory model for bicycle sharing system design: formulation and solution. Computers and Industrial Engineering, 65(1), 77-86.

Li, N., Parthasarathy R., \& Padwal, H.H (2020). The importance of public support in the implementation of green transportation in smart cities using smart vehicle bicycle communication transport. The Electronic Library, 38(5), 997-1011.

Lucic, M. C., Wan, X., Ghazzai, H. \& Massoud, Y. (2020). Leveraging intelligent transportation systems and smart vehicles using crowdsourcing: An overview. Smart Cities, 3(2), 341361.

Médard de Chardon, C., Caruso, G., \& Thomas, I. (2017). Bicycle sharing system 'success' determinants. Transportation Research Part A: Policy and Practice, 100, 202-214.

Ministry of Land, Infrastructure, Transport and Tourism. (2015). Information retried on March 18, 2021 from: https://www.mlit.go.jp/road/road_e/pdf/Bicycle.pdf.

Noland, R. B., \& Kunreuther, H. (1995). Short-run and longrun policies for increasing bicycle transportation for daily commuter trips. Transport Policy, 2(1), 67-79.

O’Brien, O., Cheshire, J., \& Batty, M. (2013). Mining bicycle sharing data for generating insights into sustainable transport systems. Journal of Transport Geography, 34, 262-273.

Ortúzar, J. D. D., Iacobelli, A., \& Valeze, C. (2000). Estimating demand for a cycle-way network. Transportation Research Part A: Policy and Practice, 34(5), 353-373.

Roldán, O. M. G., Díaz, J. R. A., \& Mellado, J. J. N. (2013). Cycling mobility accidentability in Spain. Securitas Vialis, 4(3), 97-104.

Romanillos, G. \& Austwick, M. Z. (2016) Madrid cycle track: visualizing the cyclable city. Journal of Maps, 12(5), 1218-1226

Russo, F., Rindone, C. \& Panuccio, P. (2016). Europeans plans for the smart city: from theories and rules to logistics test case. European Planning Studies, 24(9), 1709-1726.

Ryley, T. (2006) Estimating Cycling Demand for the Journey to Work or Study in West Edinburgh, Scotland. Transportation Research Record Journal of the Transportation

Research Board, 19(82), 187-193.

Shaheen, S. A., Guzman, S., \& Zhang, H. (2010). Bikesharing in Europe, the Americas, and Asia: Past, present, and future. Transportation Research Record: Journal of the Transportation Research Board, 21(43), 159-167.

Syakir Amir, Ainina Azizan, Rustam Khairi Zahari \& M.Zainora Asmawi (2020). Urban Public Space as Social Interaction Space: Case Study in Petaling Street. Journal of Tourism, Hospitality and Environment Management. 5(19). 90-101.

Stinson, M. A. \& Bhat C.R. (2003) Commuter Bicycling Route Choice: Analysis Using a Stated Preference Survey. Transportation Research Record Journal of the Transportation Research Board, 18(28), 107-115.

Zeeuw, D.D. \& Flusche, D. (2011). How a Bill Becomes a Bike Lane: Federal Legislation, Programs, and Requirements of Bicycling and Walking Projects. Planning and Environmental Law, 63(8), 8-11. 